\title{
The Effect of Mindfulness-Based Stress Reduction on Anxiety and Stress in Patients with Coronary Heart Disease after Coronary Artery Bypass Graft Surgery: A Single-Subject Study
}

\section{Rasoul Heshmati}

Department of Psychology, Faculty of Educational Sciences and Psychology, Tabriz University, Tabriz, Iran

Article Type:

Original Article

\section{Article History:}

Received: 22 Sep. 2017

Revised: 18 Aug. 2018

Accepted: 1 Sep. 2018

\section{*Correspondence:}

Rasoul Heshmati,

Department of

Psychology, Faculty

of Educational

Sciences and

Psychology, Tabriz

University, Tabriz,

Iran

psy.heshmati@gmail. com

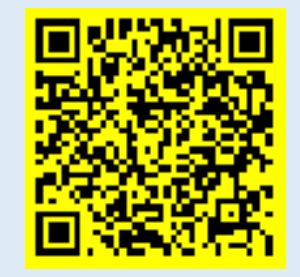

\begin{abstract}
Background and objectives: Coronary artery disease (CAD) is associated with negative emotions of anger and stress, which are one of the nonclinical risk factors of the disease. Therefore, evaluation of the effective therapeutic models alleviating the patients' negative emotions is of paramount importance. This study aimed to examine the effect of mindfulness-based stress reduction (MBSR) on anger and stress in patients with coronary heart disease after coronary artery bypass graft (CABG).

Methods: This research had an A-B single-subject design. The research population encompassed all patients with coronary heart disease referring to Shahid Madani Hospital of Tabriz, Iran during the second half of 2016 for rehabilitation measures. Four patients were selected using convenience sampling. Before the interventions, the participants completed state-trait anger expression inventory (STAXI-2, Spielberger) and depression anxiety stress scale (DASS) throughout two consecutive weeks, which led to establishing two baselines. Afterwards, they received mindfulness-based stress reduction training during seven consecutive weeks and completed the questionnaires after each intervention. Percentage of recovery, percentage of non-overlapping data (PND), standard mean difference (SMD), and effect size were used to analyze the data, and eye diagram analysis was adopted to interpret the data.

Results: The findings indicated that the mean recovery rate for all participants was 0.84 and its effect size index was 2.7. Moreover, the mean percentage of recovery and the effect size index of mindfulness intervention on the patients' anger were 0.18 and 1.38 , respectively.

Conclusion: According to the results of the study, it could be concluded that mindfulness-based stress reduction is an effective intervention to regulate stress in patients suffering from coronary heart disease.
\end{abstract}

Keywords: Mindfulness, Stress, Anger, Coronary heart disease

Copyright(C 2018, Jorjani Biomedicine Journal has published this work as an open access article under the terms of the Creative Commons Attribution License (http://creativecommons.org/licenses/by-nc/4.0/) which permits noncommercial uses of the work while it is properly cited. 


\section{Introduction}

Coronary Artery Disease (CAD) is the main cause of death in a majority of countries (1), including Iran (2 and 3 ), and will be the leading cause of mortality by 2020 (4). In Iran, CAD is the first cause of death among individuals aged $\geq 38$ years (5). This disease is associated with feelings of anger and stress. In this regard, the coronary artery bypass graft (CABG), which is a surgical procedure to restore normal blood flow to an obstructed coronary artery, imposes a lot of stress on patients (6).

Stress is defined as a physical response to external and internal stimuli. In other words, stress is a condition or an emotion in which a person perceives that requests and expectations from him are beyond his available resources, facilities, and potentials. In addition, anger is an emotional state, the severity of which varies from mild stimulation to severe anger and is accompanied with physiological changes (e.g., heart palpitations and hypertension). According to some researchers, hostility and anger are one of the non-clinical risk factors that induce coronary artery atherosclerosis (7).

A large number of studies have shown that the experience of anger increases the risk of CAD independent from risks associated with social, demographic and biological factors (8). Furthermore, numerous prospective epidemiological studies have revealed a significant relationship between anger and CAD (9). Anger is correlated with poor prognosis in patients with $\mathrm{CAD}$ and is considered as a risk factor for this condition (10). Research findings have confirmed the relationship between anger and the long-term and serious health risk factors, such as hypertension and cardiovascular diseases (11).
On the other hand, stress has been considered as a predictor and risk factor for $\mathrm{CAD}$, and many studies have been carried out in this regard (12). Acute and sudden stresses as well as chronic stresses have negative consequences. Moreover, acute stress can lead to sudden clinical events, including a heart attack. In addition to the effects of acute and short-term stressors, the consequences of chronic stressors are considered as a risk factor for CAD as well. Some of the widely studied factors include job stress, low social support, and low socioeconomic status. The relationship between occupational stress and CAD has been assessed and confirmed in a number of studies (13). Emotion-focused coping techniques and mindfulness-based stress reduction method play a critical role in regulating the negative emotions among patients with CAD.

Mindfulness is purposeful attention to the present moment with compassion, curiosity and acceptance, which is discovering how to live at the moment pleasantly rather than worrying about the past and future (14). Mindfulness-based stress reduction (MBSR) technique was developed by Kabat-Zinn (15). During this eight-session intervention, participants are taught to communicate with their inner and outer worlds in the moment and with non-judgmental awareness. Moreover, MBSR uses a combination of body awareness, breathing exercises, mindfull yoga, mindful inspiration, fluid meditation, records of pleasant experiences, and records of unpleasant experiences. By facilitating the evaluation of the positive process, mindfulness reduces the devastating consequences of stressful conditions. It also uses dishabituation for inappropriate coping strategies to reduce the problems of stressful conditions (16). The results of a study, which aimed to determine the effects of the MBSR program on reducing anger and stress in 
patients with hypertension, showed that this intervention reduced anger and stress levels in patients with hypertension, compared to the control group (17).

Wright, Day, Howells (18) carried out a study to determine the effect of mindfulness on anger problems, reporting that MBSR treatments effectively reduced the level of anger. In a review study, the effect of MBSR treatments on the increased mental health of individuals with chronic diseases was examined, and it was found that this treatment reduced the symptoms of depression, anxiety, stress, and anger in the experimental group, compared to the control group (19).

Despite the importance of this issue, little research has been conducted on the effectiveness of this type of intervention in reducing the negative emotions of patients with CAD. In other words, previous studies did not control the effect of surgery, which is a stressful condition and adversely affects patients' emotions. Moreover, the effect of mindfulness intervention on the feelings of anger and stress among CAD patients was not considered for individuals (due to their continued need for close communication) after surgery. Furthermore, the post-surgical mental conditions of these patients have been ignored. Therefore, this study aimed to evaluate the effect of MBSR technique on anger and stress among patients with CAD after CABG using a single-subject study.

\section{Materials and Methods}

An A-B single-subject design was used in this study. Since the mental status of the participants was continuously investigated and monitored by the researcher with regard to the existence of a surgery and its effect on emotions, such as anxiety, depression and stress for two months through using phone calls, messages and in-person visits, no other designs could be employed and the singlesubject design was adopted. The statistical population of the study consisted of all patients with coronary heart disease (CHD) in Tabriz, Iran. From those patients undergoing a surgery in Shahid Madani Hospital of Tabriz, four CDA patients passing the rehabilitation period were selected using convenience sampling. Inclusion criteria were: (1) history of CABG; (2) minimum age of 20 years; (3) ability to communicate verbally; (4) ability to fill the questionnaires; (5) elementary education and higher levels; and (6) consent to participate in the study. Exclusion criteria consisted of poor general medical conditions based on the physician's opinion during the treatment course. After selecting the participants and explaining the objectives of the research while adhering to the ethical considerations, the participants completed the State-Trait Anger Expression Inventory (STAXI-2, Spielberger) and Depression Anxiety Stress Scale (DASS) throughout two consecutive weeks prior to the interventions, which led to establishing two baselines.

After each intervention, they completed the questionnaires again weekly. Regarding the A-B design, the research variables (i.e., anxiety and stress) were measured in two phases: baseline phase (A) and experimental phase (B). In the phase A, which included two baselines, the participants filled the questionnaires within two consecutive weeks in the cardiac rehabilitation department of the hospital, which resulted in determining the levels of the concerned emotions prior to the intervention. In the phase B, the participants attended a group-training course on MBSR intervention for seven consecutive weeks in a relaxed atmosphere in the rehabilitation ward, 
and completed questionnaires in the same place after each intervention. In this way, the patients' levels of anger and stress were determined after the intervention.

The MBSR intervention was developed according to Kabat-Zinn's (2005) standard to be implemented as an eight-week treatment program once a week in the form of 150- minute sessions. A summary of the training sessions and their contents are presented in Table 1.

Table 1. Summary of MBSR Group Sessions

\begin{tabular}{|c|c|c|}
\hline Session & Content & Daily practices in a week \\
\hline First & $\begin{array}{l}\text { 1) Presenting the concepts of mindfulness and } \\
\text { stress and their effects on life; 2) Illustrating a } \\
\text { holiday and promoting the will to participate in } \\
\text { meetings; 3) Eating raisins; 4) Mindful } \\
\text { examination of body; and 5) Examining } \\
\text { experiences }\end{array}$ & $\begin{array}{l}\text { 1) Listening to CD1 2) Solving } \\
\text { the nine-point puzzle; 3) } \\
\text { Paying attention to inner } \\
\text { modes }\end{array}$ \\
\hline Second & $\begin{array}{l}\text { 1) Mindful examination of body; 2) Breathing } \\
\text { exercises; and 3) Addressing exercises } 1 \text { and } 2\end{array}$ & $\begin{array}{l}\text { 1) Listening to CD1; 2) } \\
\text { Breathing exercises; and } 3 \text { ) } \\
\text { Stretching (Yoga) }\end{array}$ \\
\hline Third & $\begin{array}{l}\text { 1) Mindful Yoga; 2) Breathing exercises; and 3) } \\
\text { Checking the experiences obtained from the } \\
\text { exercises }\end{array}$ & $\begin{array}{l}\text { 1) Listening to CD1 and CD2 } \\
\text { alternatively, 2) Breathing } \\
\text { exercises; and 3) Recording } \\
\text { inconvenient events }\end{array}$ \\
\hline Fourth & $\begin{array}{l}\text { 1) Mindful Yoga; 2) Breathing and body } \\
\text { exercises; 3) Checking experiences obtained } \\
\text { from the exercises; 4) Practicing interactive } \\
\text { dialogue; 5) Practicing thoughts-emotions-body } \\
\text { senses-behavior relationships }\end{array}$ & $\begin{array}{l}\text { 1) Listening to } \mathrm{CD} 1 \text { and } \mathrm{CD} 2 \\
\text { alternatively, 2) Breathing } \\
\text { exercises; and 3) Awareness of } \\
\text { stress reactions }\end{array}$ \\
\hline Fifth & $\begin{array}{l}\text { 1) Mindful meeting; 2) Mindful walking; and 3) } \\
\text { Checking experiences }\end{array}$ & $\begin{array}{l}\text { 1) Listening to the } \mathrm{CD} 3 \text { every } \\
\text { other day and listening to } \mathrm{CD} 1 \\
\text { and } \mathrm{CD} 2 \text { the other days; } 2) \\
\text { Awareness of the reactions }\end{array}$ \\
\hline Sixth & $\begin{array}{l}\text { 1) Fluid meditation; 2) Standing and mindful } \\
\text { yoga; and 3) Checking experiences }\end{array}$ & $\begin{array}{l}\text { 1) Listening to the CD3 every } \\
\text { other day and listening to CD1 } \\
\text { and CD2 the other days; 2) } \\
\text { Awareness of everything that } \\
\text { enters the body }\end{array}$ \\
\hline Seventh & $\begin{array}{l}\text { 1) Three-Minute Breathing Space (3MBS); 2) } \\
\text { Fluid meditation; 3) Practicing decisive } \\
\text { behavior; 4) Checking experiences }\end{array}$ & $\begin{array}{l}\text { 1) Doing the exercises in the } \\
\text { three CDs without listening to } \\
\text { them; 2) Paying attention to } \\
\text { nutrition }\end{array}$ \\
\hline Eighth & $\begin{array}{l}\text { 1) Mindful examination of body; 2) Compassion } \\
\text { meditation; 3) Checking experiences; 4) Prayer } \\
\text { for health and alliance and the end }\end{array}$ & $\begin{array}{l}\text { 1) Returning to the exercises in } \\
\text { the three CDs and performing } \\
\text { them on one's wish }\end{array}$ \\
\hline
\end{tabular}




\section{Research Instruments}

\section{-Depression Anxiety Stress Scale (DASS)}

The DASS encompasses 21 items on the symptoms of negative emotions (depression, anxiety and stress). In this study, the stress component was used to measure the participants' level of stress. The stress subscale includes phrases such as difficulty in relaxation, nervous tension, irritability and restlessness. Henry and Crawford (20)

Compared this instrument with two other tools in a sample of 1771 cases in the United Kingdom. They reported the Cronbach's alpha coefficients to be 0.93 for the stress scale and 0.97 for the whole scale. In the Iranian sample, a study (21) also confirmed the reliability of this scale at the Cronbach's alpha coefficient of 0.82 for the stress subcategory.

\section{-State-Trait Anger Expression Inventory-2 (STAXI-2, Spielberger)}

This 57 -item inventory was developed by Spielberger (22) and consists of six scales, five sub-scales, and anger expression indices. Six scales are as follows: 1) trait anger scale with 15 items measuring the intensity of anger and a person's tendency to express it verbally or physically at a specified time; 2) anger strike scale with 10 items measuring individual differences in the tendency to experience anger; 3) anger expression scale with eight items measuring the frequency for feelings of anger directed verbally or aggressively toward other persons or objects in the environment; 4) anger expression-in scale with eight items measuring the frequency of the experienced, but not expressed, feeling of anger; 5) anger controlout scale with eight items measuring the frequency of controlling the outward expression of anger; and 6) anger control-in scale with eight items measuring the frequency of cases when an individual tries to control his anger through relaxing or calming down. The inventory is scored based on a four-point Likert scale from one (never ever) to four (very much). Spielberger (22) reported the validity and credibility of this inventory as acceptable; the high internal consistency among the scales and the sub-scales of anger and its positive relationship with other scales of anger and hostility reflect its acceptable validity. In addition, a study in Iran (23) confirmed the validity of this questionnaire. Cronbach's alpha coefficient was used to determine validity and its value was 0.79 for the total score of anger. To determine the validity, the correlation of each item with its relevant following score was examined and the correlation coefficients ranged from 0.29 to $0.75(23)$.

\section{Data Analysis}

Data analysis was performed using mean, standard deviation, percentage of recovery, percentage of non-overlapping data (PND), standard mean difference (SMD), effect size, and eye diagram analysis.

\section{Results}

According to Table 2, the percentages of recovery for the participants 1-4 with regard to the anger variable were $8 \%, 26 \%, 12 \%$ and $28 \%$, respectively, with the mean recovery rate of $18 \%$, indicating that the rate of anger remained unchanged in the first and third participants, and the second and fourth participants' rate of recovery was extremely low. The mean percentage of recovery in the participants was $18 \%$, suggesting the ineffectiveness of intervention in improving 
anger control among the participants. Regarding the percentage of PND, the rates of recovery were $28 \%, 71 \%, 14 \%$ and $85 \%$ respectively, which means that the treatment failed to improve the anger control in the first and third participants. However, it managed to reduce anger in average in the second and fourth participants. The mean PND for all participants was $50 \%$, showing the low effectiveness of intervention in reducing anger among the participants. The effect size and the standard mean difference (SMD) obtained for this variable were 1.38 and 1.47 , respectively, which are within a large and acceptable range. According to the results, MBSR training had a relatively desirable effect on anger of patients with CHD.

Table 2. Mean, Standard Deviation, Percentage of Recovery, PND, PND Mean, SMD, and effect Size of Anger in the Participants

\begin{tabular}{|c|c|c|c|c|}
\hline & First Participant & Second Participant & Third Participant & Fourth Participant \\
\hline Baseline 1 & 114 & 159 & 103 & 155 \\
\hline Baseline 2 & 132 & 134 & 96 & 142 \\
\hline Mean & 123 & 146.5 & 99.5 & 148.5 \\
\hline SD & 12.72 & 17.67 & 4.94 & 9.19 \\
\hline Treatment session 1 & 121 & 151 & 98 & 163 \\
\hline Treatment session 2 & 117 & 142 & 96 & 130 \\
\hline Treatment session 3 & 114 & 106 & 100 & 109 \\
\hline Treatment session 4 & 112 & 94 & 104 & 125 \\
\hline Treatment session 5 & 119 & 104 & 98 & 117 \\
\hline Treatment session 6 & 117 & 101 & 91 & 118 \\
\hline Treatment session 7 & 113 & 108 & 87 & 106 \\
\hline Mean & 116.1 & 115.1 & 96.2 & 124 \\
\hline SD & 3.18 & 22.03 & 5.67 & 19.11 \\
\hline $\begin{array}{l}\text { Treatment } \\
\text { efficiency }\end{array}$ & 8.13 & 26.27 & 12.5 & 28.6 \\
\hline $\begin{array}{l}\text { Percentage of non- } \\
\text { overlapping data } \\
\text { (PND) }\end{array}$ & 28.5 & 71.4 & 14.2 & 85.7 \\
\hline $\begin{array}{l}\text { Mean of treatment } \\
\text { efficiency }\end{array}$ & 18.87 & & & \\
\hline Mean PND & 49.95 & & & \\
\hline Baseline Mean & 129.3 & & & \\
\hline SD Base line & 11.13 & & & \\
\hline Treatment Mean & 112.85 & & & \\
\hline Treatment SD & 12.52 & & & \\
\hline Effect size & 1.38 & & & \\
\hline SMD & 1.47 & & & \\
\hline
\end{tabular}

In addition to the above indices, the eye diagram analysis was used to examine the variation of anger during the intervention sessions (Figure 1). Based on Figure 1, the trend line declined for the participants 2 and 4 , indicating a decrease in the level of anger.
However, the trend line for the first and third participants was not downward. According to the results, the intervention had no satisfactory effect on all the participants even though moderate variations occurred during the intervention for the two cases. The 
results of eye diagram analysis, consistent with single-subject indices, showed a relative decrease in anger for some cases as a result of MBSR training program.
In sum, the findings of various indices for the efficacy of the present intervention suggested that despite the desirability of the effect size and standard mean difference, the other three main indices (namely percentage of recovery, PND and eye diagram analysis) indicated low effectiveness of the intervention in reducing anger.
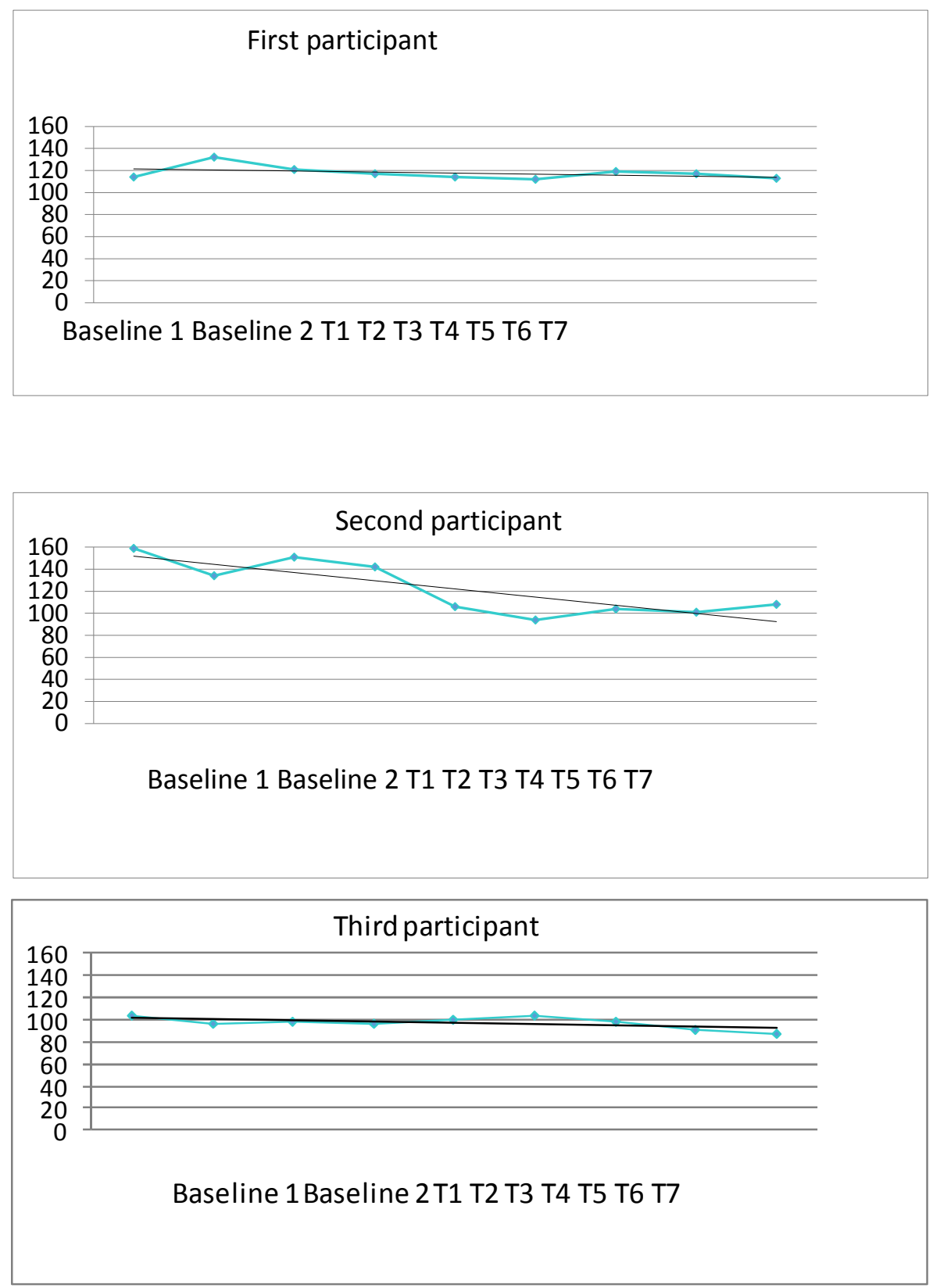



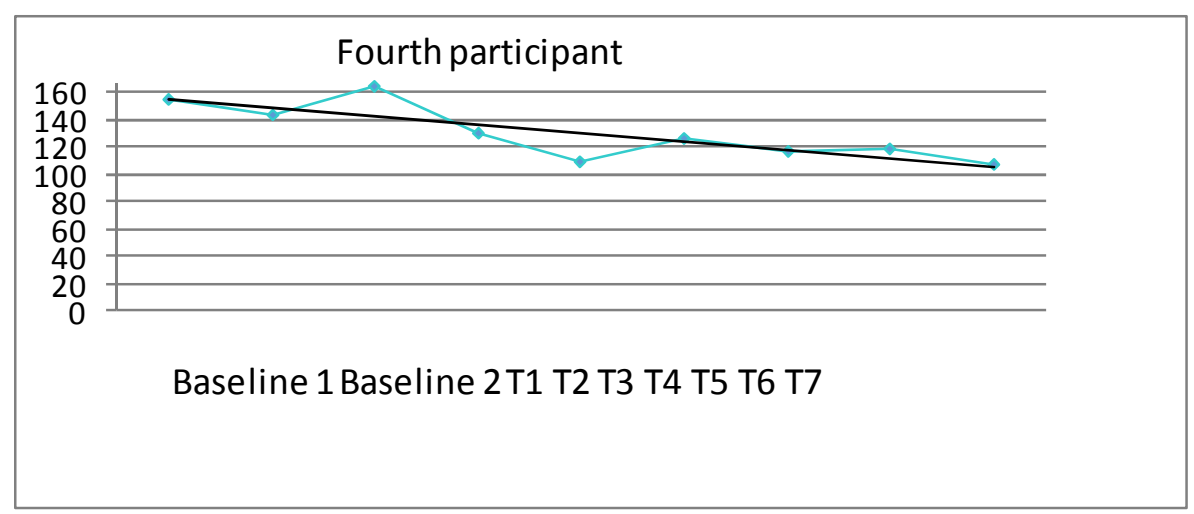

Figure 1. Eye Diagram Analysis of Anger Variations

In Table 3, the percentages of recovery for the participants 1 to 4 regarding the stress variable were $84 \%, 58 \%, 100 \%$ and $93 \%$, respectively. Accordingly, the rate of stress reduction and recovery was extremely high for the participants 1, 3 and 4, and moderate for the second participant. The mean recovery rate of all participants was $84 \%$, showing the high efficacy of intervention in reducing the stress of the concerned patients. With regard to the PND percentage, the percentages of recovery were $71 \%, 57 \%, 85 \%$ and $85 \%$, respectively, showing the lower efficiency of the treatment for reducing stress in the second participant and its moderate efficacy for the other participants. The mean rate of recovery for the participants was $75 \%$, showing the moderate effectiveness of the intervention to reduce the stress among the participants.

The effect size and the standard mean difference (SMD) for this variable were 2.7 and 6.18 , respectively, both of which are within the large and desirable range of variation. In addition, the findings from these two indices indicated the relatively high effectiveness of MBSR training in reducing stress in patients with CHD.
In addition to the abovementioned indices, the eye diagram analysis was used to examine the variation of stress during the intervention sessions (Figure 2). Based on this figure, the trend line declined for the participants, presenting a decrease in the level of stress. As shown in the figure, the overall slope of the variation trend was relatively steep, which reflected the significant variation in the variable under consideration. This finding, in line with the aforementioned indices, suggested the effectiveness of the MBSR training program intervention in reducing stress among the concerned patients. In short, the concerned indices showed the high desirable efficacy of the present intervention in reducing stress based on the MBSR program in patients with CHD. 
Table 3. Mean, Standard Deviation, Percentage of Recovery, PND, PND Mean, SMD, and Effect Size of Stress in the Participants

\begin{tabular}{|c|c|c|c|c|}
\hline & $\begin{array}{l}\text { First } \\
\text { Participant }\end{array}$ & Second Participant & Third Participant & Fourth Participant \\
\hline Baseline 1 & 24 & 36 & 10 & 16 \\
\hline Baseline 2 & 28 & 41 & 8 & 14 \\
\hline Mean & 26 & 38.5 & 9 & 15 \\
\hline SD & $82 / 2$ & 3.53 & 1.4 & 1.4 \\
\hline Treatment session 1 & 24 & 42 & 8 & 16 \\
\hline Treatment session 2 & 26 & 40 & 2 & 10 \\
\hline Treatment session 3 & 16 & 42 & 4 & 10 \\
\hline Treatment session 4 & 22 & 26 & 4 & 8 \\
\hline Treatment session 5 & 12 & 20 & 0 & 2 \\
\hline Treatment session 6 & 12 & 18 & 1 & 2 \\
\hline Treatment session 7 & 4 & 16 & 0 & 1 \\
\hline Mean & 16.5 & 29.1 & 2.7 & 7 \\
\hline SD & 7.89 & 11.82 & 2.87 & 5.56 \\
\hline Treatment efficiency & 84.6 & 58.4 & 100 & 93 \\
\hline $\begin{array}{l}\begin{array}{l}\text { Percentage of non- } \\
\text { overlapping } \\
\text { (PND) }\end{array} \\
\text { data }\end{array}$ & 71.4 & 57.1 & 85.7 & 85.7 \\
\hline $\begin{array}{l}\text { Mean of treatment } \\
\text { efficiency }\end{array}$ & 84 & & & \\
\hline Mean PND & 74.9 & & & \\
\hline Baseline Mean & 22.1 & & & \\
\hline SD Baseline & 2.28 & & & \\
\hline Treatment Mean & 7.99 & & & \\
\hline Treatment SD & 7.03 & & & \\
\hline Effect size & 2.70 & & & \\
\hline SMD & 6.18 & & & \\
\hline
\end{tabular}



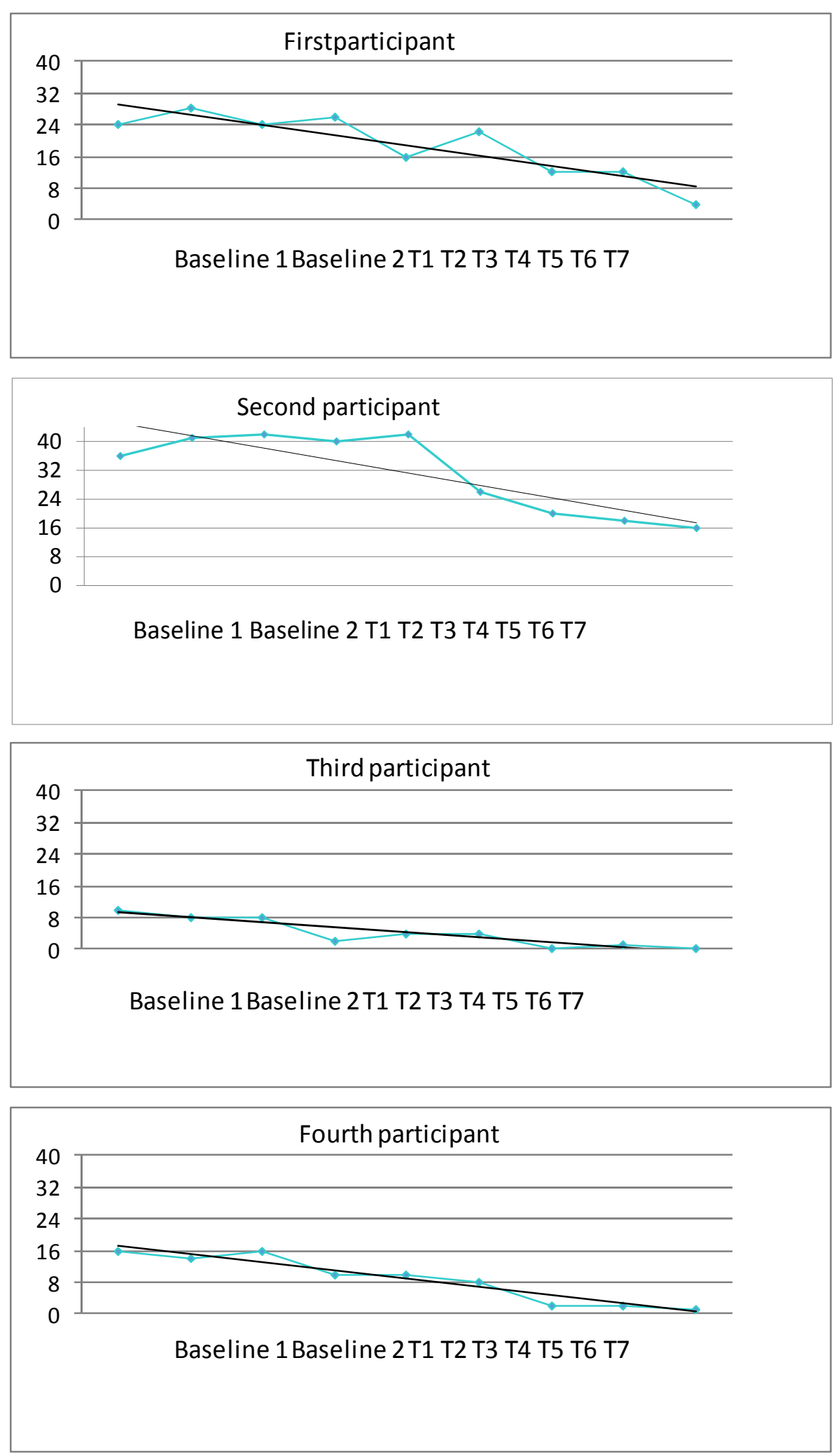

Figure 2. Eye Diagram Analysis of Stress Variations 


\section{Discussion}

Concerning the first hypothesis of the study, the findings showed that MBSR training led to a relative reduction of anger in CHD patients. In this regard, our findings are consistent with the results obtained by Boolemier et al. (8) and Wright's et al. (18). Anger is one of the emotional factors that play a role in heart disease, as reported by a large number of studies. It has been suggested that increasing anger in the body and its lack of expression leads to an increase in blood pressure and lack of experiencing anger and its suppression results in lipid deposits and a decrease in cardiac function (24). This issue has been extensively explored in studies on the personality type A. According to these studies, among the factors that affect heart disease are two components of anger and hostility (2).

However, it seems that mere experience of anger does not lead to cardiac diseases and it is the non-expressed and internalized anger that might lead to heart diseases. Through increasing awareness of emotions in the first step, clarifying and distinguishing different emotions in the second step, and increasing the expression of emotions in the third step, MBSR provides the grounds for releasing emotions. This can play a key role in reducing symptoms in patients with heart diseases. Experiencing anger along with compassion and away from judgment strengthens mental functions and regulates moods. On the other hand, the experience of anger with mindfulness makes it possible to use more effective strategies instead of ineffective coping strategies for interpersonal relationships and life problems.

Regarding the second hypothesis of the present study, the results showed that the MBSR program reduced stress in the participants, which is in congruence with the results obtained by Goyal et al. (26), Richardson et al (27), and Parswani, Sharma, and Iyengar (28). Mindfulness training reduces psychological distress, improves mental, physical, emotional and spiritual wellbeing (29-43), and decreases physical symptoms (40-35). It could be stated that frequent use of various techniques during treatment sessions improves and reduces stress in individuals with CHD. In fact, the physiological hyper-excitation induced in stressful situations enhances the levels of epinephrine and norepinephrine hormones as well as the heart rate of individuals. This response might increase stress and blood pressure along with heart rate.

To explain the results, it could be expressed that the MBSR provides the grounds for increasing the level of selfesteem, and attention and compassion bring stress relief. Those experiencing high levels of stress spend a lot of time on daily life activities but not on taking care of themselves. Through mindfulness training sessions, participants learn to treat themselves in a different way and spend more time for themselves instead of stressful activities. Stress is a kind of extra burden, which is always accompanied with psychological difficulties. Psychological stress causes tension in smooth and skeletal muscles in the body, both of which increase the blood pressure and extra burden on the heart. MBSR reduces stress in $\mathrm{CHD}$ patients through decreasing such burdens by self-love and selfcompassion mechanisms, admission and experience rather than avoidance, and mood adjustment. 


\section{Conclusion}

According to the results of the current research, it could be concluded that MBSR is an effective method for reducing negative emotions in CAD patients. MBSR can use emotional adjustment processes to decrease negative emotions of anger and stress in patients with CAD. Accordingly, MBSR can be used as one of the most basic therapies along with medication to improve cardiac function and to regulate the emotions of patients with CAD in hospitals and cardiology clinics. Some of the major drawbacks of the present study were its single-subject design and small sample size, which limited the generalizability of the results. Therefore, it is suggested that the topic of the current research be regarded for CHD patients by considering different demographic characteristics, and eliminating personal traits and controlling them. It is also recommended that the effects of other therapies, such as medication, be controlled in future studies.

\section{Acknowledgements}

We would like to thank all physicians, nurses and the staff of Tabriz Shahid Madani Hospital for assisting us in performing this research.

\section{Declarations}

\section{Funding source(s)}

This article was extracted from a master's thesis (No. 2384411) approved at University of Tabriz. Hereby, we extend our gratitude to the participants for their cooperation with our researcher.

\section{Ethics approvals and consent to participate}

Not applicable

\section{Conflict of interest}

We declare that we have no financial or nonfinancial conflicts of interest related to the subject matter or materials discussed in the article. 


\section{References}

1. Barzin M, Mirmiran P, Afghan M, Azizi F. Distribution of 10-year risk for coronary heart disease and eligibility for therapeutic approaches among Tehranian adults. Public health. 2011 Jun $30 ; 125(6): 338-44$.

2. Go AS, Mozaffarian D, Roger VL, Benjamin EJ, Berry JD, et al. Executive summary: heart disease and stroke statistics-2013 update: a report from the American Heart Association. circulation. 2013 Jan 1; 127(1):143-52.

3. Baljani A, Rahimi J, Amanpour A, Salimi S, Parkhashjoo M. The effect of nursing intervention in increasing self-efficacy and decreasing risk factor of cardiovascular diseases. Journal of Nursing and Midwifery of Tehran University (hayat) 2009; 17(1):45-54.

4. Benjamin I, Griggs RC, Wing EJ, Fitz JG. Andreoli and Carpenter's Cecil Essentials of Medicine E-Book. Elsevier Health Sciences; 2015 Apr 12.

5. Vahedian Azimi A, Alhani F, Ahmadi F, Kazemnejad AN. Effect of family-centered empowerment model on the life style of myocardial infarction patients. Journal of Critical Care Nursing. 2010 Feb 15; 2(4):1-2.

6. Cardona S, Pasquel FJ, Fayfman M, Peng L, Jacobs $\mathrm{S}$, et al. Hospitalization costs and clinical outcomes in CABG patients treated with intensive insulin therapy. Journal of Diabetes and its Complications. 2017 Apr 30; 31(4):742-7.

7. Ezhov MV, Afanasieva OI, Il'ina LN, Safarova MS, Adamova IY, et al. Association of lipoprotein (a) level with short-and long-term outcomes after CABG: The role of lipoprotein apheresis. Atherosclerosis Supplements. 2017 May 31.

8. Bohlmeijer E, Prenger R, Taal E, Cuijpers P. The effects of mindfulness-based stress reduction therapy on mental health of adults with a chronic medical disease: a meta-analysis. Journal of psychosomatic research. 2010 Jun 30; 68(6):53944.
9. Yamaguchi A, Kim MS, Oshio A, Akutsu S. The role of anger regulation on perceived stress status and physical health. Personality and Individual Differences. 2017 Oct 1; 116: 240-5.

10. Stepteto A. Moses J. Edwards S. Matthew SA. Exercise and responsivity to metal stress: Discrepancies between the subjective and phychological effects of aerobic training.Int $\mathrm{J}$ Sport Psycho. 2003.24:110-129.

11. Burns JW, Bruehl S, France CR, Schuster E, Orlowska D, et al. Endogenous opioid function and responses to morphine: the moderating effects of anger expressiveness. The Journal of Pain. 2017 Mar 30.

12. Bot I, Kuiper J. Stressed brain, stressed heart? The Lancet. 2017 Feb 25; 389 (10071):770-1.

13. Dimsdale JE. Psychological stress and cardiovascular disease. Journal of the American College of Cardiology. 2008 Apr 1; 51(13):123746.

14. Alidina S. Mindfulness for dummies. John Wiley \& Sons; 2014 Nov 11.

15. Kabat-Zinn J. Coming to our senses: Healing ourselves and the world through mindfulness. Hachette UK; 2005.

16. Garnefski N, Kraaij V, Spinhoven P. Negative life events, cognitive emotion regulation and emotional problems. Personality and Individual differences. 2001 Jun 30; 30(8):1311-27.

17. Omidi A, Momeni R, Akbari T, Ensia. The Effectiveness of Mindfulness-Based Stress Management on the Quality of Life of Cardiovascular Patients. Thought and behavior in clinical psychology. Dec. 21, 2016; 11 (42): 7-16.

18. Wright S, Day A, Howells K. Mindfulness and the treatment of anger problems. Aggression and Violent Behavior. 2009 Oct 31; 14(5):396401.

19. Bohlmeijer E, Prenger R, Taal E, Cuijpers P. The effects of mindfulness-based stress reduction therapy on mental health of adults with a chronic medical disease: a meta-analysis. Journal of 
psychosomatic research. 2010 Jun 30; 68(6):53944.

20. Henry JD, Crawford JR. The short-form version of the Depression Anxiety Stress Scales (DASS-21): Construct validity and normative data in a large non-clinical sample. British journal of clinical psychology. 2005 Jun 1; 44(2):227-39.

21. Pahlavanzadeh S, Navidian A, Yazdani M. The effect of psycho-education on depression, anxiety and stress in family caregivers of patients with mental disorders. Journal of Kermanshah University of Medical Sciences (J Kermanshah Univ Med Sci). 2010 Sep 22; 14(3).

22. Spielberger CD. Sate-Trait Anger Expression Inventory-2: STAXI-2. PAR, Psychological Assessment Ressources; 1999.

23. Hosseini SH, Mokhberi V, Mohammadpour RA, Mehrabianfard M, Lashak NB. Anger expression and suppression among patients with essential hypertension. International journal of psychiatry in clinical practice. 2011 Sep 1; 15(3): 214-8.

24. Siegman AW, Smith TW, editors. Anger, hostility, and the heart. Psychology Press; 2013 May 13.

25. Denollet J. DS14: standard assessment of negative affectivity, social inhibition, and Type D personality. Psychosomatic medicine. 2005 Jan 1; 67(1):89-97.

26. Goyal M, Singh S, Sibinga EM, Gould NF, Rowland-Seymour A, et al. Meditation programs for psychological stress and well-being: a systematic review and meta-analysis. JAMA internal medicine. 2014 Mar 1; 174(3):357-68.

27. Richardson S, Shaffer JA, Falzon L, Krupka $\mathrm{D}$, Davidson KW, et al. Meta-analysis of perceived stress and its association with incident coronary heart disease. The American journal of cardiology. 2012 Dec 15; 110(12):1711-6.

28. Parswani MJ, Sharma MP, Iyengar SS. Mindfulness-based stress reduction program in coronary heart disease: A randomized control trial. International journal of yoga. $2013 \mathrm{Jul}$; $6(2): 111$.
29. Colle KF, Vincent A, Cha SS, Loehrer LL, Bauer BA, et al. Measurement of quality of life and participant experience with the mindfulnessbased stress reduction program. Complementary Therapies in Clinical Practice. 2010 Feb 28; 16(1):36-40.

30. Karimi L, Ramezani V, Ahmadi M, Heshmati $\mathrm{R}$, Jafar E. Psychometric properties of Torrance test (Persian version) of creative thinking (A form). Procedia-Social and Behavioral Sciences. 2010 Jan 1; 5: 1429-33.

31. Bayrami M, Abad TH, Ghoradel JA, Daneshfar S, Heshmati R, Moslemifar M. The role of positive and negative affectivity, optimism, pessimism, and information processing styles in student psychological adjustment. Procedia-Social and Behavioral Sciences. 2012 Jan 1; 46: 306-10.

32. Heshmati RA, Ghorbani NI, Rostami RE, Ahmadi MO, Akhavan HA. Comparative Study of Alexithymia in Patients with Psychotic Disorders, Non Psychotic and Normal People. Scientific Journal of Hamadan University of Medical Sciences. 2010 Jan 1; 17(1):56-61.

33. Shaker A, Heshmati R, Rahimi MP. Investigation of Marital adjustment in people with secure, preoccupied, dismissing and fearful attachment styles. Procedia-Social and Behavioral Sciences. 2010 Jan 1; 5: 1823-6.

34. Ghamari Givi H, Moulavi P, Heshmati R. Exploration of the Factor Structure of Positive and Negative Syndrome Scale in Schizophernia Spectrum Disorder. Journal of Clinical Psycology. 2010 Dec 15; 2(2):1-0.

35. Kieviet-Stijnen A, Visser A, Garssen B, Hudig W. Mindfulness-based stress reduction training for oncology patients: Patients' appraisal and changes in well-being. Patient education and counseling. 2008 Sep 30; 72(3):436-42.

36. Bayrami M, Heshmati R, Karami R. Anxiety: Trait/Sate, Sensation Seeking and Marital Satisfaction in Married Women. Procedia-Social and Behavioral Sciences. 2011 Jan 1; 30:765-70.

37. Heshmati R, Ghorbani F. the effect of Mindfulness-based Stress Reduction (MBSR) program on physical functioning and health related quality of life (HRQOL) in peopel with 
Coronary Artery Disease (CAD). Iranian journal of Cardiovascular Nursing 5 (3), 16-25

38. Heshmati R, Hatami J, Bahrami EH, Sadeghian S. The effect of the biological status of CAD patients on health related quality of life: the mediating role of illness representations. journal of Research in Behavioural Sciences. 12 (3), 328341

39. Heshmati R, Allahverdipour H, Tabatabaei MG, Kamrani S. Toronto Alexithymia Scale (TAS-20): A study of patients with schizophrenia spectrum disorders. Procedia-Social and Behavioral Sciences. 2011 Jan 1; 30: 771-5.

40. Heshmati R. Structural Relationships among Functional Status, Health Beliefs and BMI in Patients with CAD: The Mediator Role of Cardiac Self-Efficacy. Journal of Health and Care. 2016 Jan 1; 18(3):191-206.

\section{How to cite:}

Heshmati R. The Effect of Mindfulness-Based Stress Reduction on Anxiety and Stress in Patients with Coronary Heart Disease after Coronary Artery Bypass Graft Surgery: A Single-Subject Study. Jorjani Biomedicine Journal. 2018; 6(2): 33-47. DOI: 10.29252/jorjanibiomedj.6.2.33 